\title{
SOBRE OS MODELOS DE MAGNITUDE-FREQÜÊNCIA E DE ESTABILIDADE DE VERTENTES
}

\author{
Antonio Carlos Colângelo ${ }^{1}$
}

\begin{abstract}
Resumo: A primeira parte deste artigo é dedicada à abordagem de magnitude e freqüência, que representa uma nova perspectiva para a avaliação de processos em Geomorfologia. Sua proposta remonta ao trabalho de Woman e Miller, de 1960, que ganhou uma nova perspectiva com o artigo de Ahnert de 1987, que integra numa função semilogarítmica o montante da contribuição efetiva de uma variedade de tipos de eventos considerados num estudo de processos. Esta abordagem é aplicável indistintamente em todas as escalas de trabalho, para todos os tipos de eventos, tendo por objetivo obter predições mais acuradas no tempo e no espaço. A segunda parte deste artigo trata da evolução dos modelos aplicados à estabilidade de vertentes, criados na Mecânica dos Solos e adaptados na Geomorfologia, desde Coulomb, em 1776, até Fredlund, em 1987. Para ilustrar as assertivas e comentários são apresentados, nas duas partes, exemplos com dados levantados numa área tropical úmida.
\end{abstract}

Palavras-chave: Análise de magnitude-freqüência; Análise de processos; Estabilidade de encostas; Limiares em Geomorfologia.

\section{A abordagem de magnitude-frequiência}

WOLMAN e MILLER (1960) foram precursores na proposição da abordagem de magnitude-freqüência ao estudo dos processos geomorfológicos. Estes autores Escreveram que "quase todo mecanismo específico necessita, para atuar, que seja ultrapassado certo limite de forças..." Desta frase, gostaríamos de excluir apenas a expressão "quase", porque nos parece ser condição necessária para a ocorrência de qualquer processo na natureza, que uma força ativa ou solicitante supere uma força passiva ou solicitada.

É necessário inicialmente esclarecer alguns pontos fundamentais. Em primeiro lugar, salientar a importância da determinação de limiares nos estudos sobre processos, e em segundo, tratar do conceito de "processo". No mundo físico, os processos (eventos, sucessos, acontecimentos ou fenômenos) são entidades temporal e espacialmente descontínuas, desencadeados a partir da interação de agentes físicos, químicos ou biológicos, e se manifestam nas mais variadas escalas de duração, de modo que se superpõem no tempo e/ou no espaço. Sendo assim, podem ser caracterizados quantitativamente através de quatro variáveis, a saber: (1) magnitude (material, espacial ou temporal), (2) freqüência (temporal ou espacial), (3) duração e (4) intensidade (média ou momentânea).

A variável magnitude pode também se referir a uma grandeza temporal como, por exemplo, os períodos de estiagem, ou períodos sem chuva, muito embora seja mais comum referi-se a grandezas materiais ou espaciais. Freqüência geralmente faz referência a uma grandeza temporal, entretanto, pode ser assimilada a uma grandeza espacial. Sobre este conceito de "freqüência espacial de ocorrência de eventos", os trabalhos de COLÂNGELO e CRUZ (1997), CROZIER e GLADE (1997) e COLÂNGELO e CRUZ (2000), tratam de sua aplicação à analise espacial de processos de movimentos de massa.

A Intensidade média de um fenômeno é determinada pela razão entre sua magnitude e sua duração. Portanto, eventos de magnitudes e durações distintas podem ainda assim apresentar a mesma intensidade média, sendo, entretanto muito diversos. Existe uma outra situação possível: por exemplo, dois eventos reais podem apresentar magnitudes e durações quase idênticas, tendo, portanto intensidades médias equivalentes e mesmo assim, podem apresentar distribuição de intensidades momentâneas completamente diferentes. Este dado pode ser de grande importância tanto nos estudos de processos erosivos desencadeados pela ação do escoamento superficial, como naqueles voltados para a estabilidade de vertentes, fortemente controlados pelo escoamento subsuperficial. A "distribuição momentânea de intensidades caracteriza 0 evento de chuva quanto ao ritmo de transferência de matéria e energia para a superfície do terreno, sendo dado fundamental na análise dos fenômenos erosivos na escala de vertente".

Frank AHNERT publica em 1987 An approach to the identification of morphoclimates, onde apresenta uma abordagem de magnitude-frequêencia aplicável a diversos tipos de eventos,

1 Departamento de Geografia, FFLCH, Universidade de São Paulo, accolang@usp.br 
como no caso dos eventos de chuva, tão importantes para os geomorfólogos nos estudos de processos. Não se sabe ao certo, mas só após a data de publicação deste artigo é que surgiram novos trabalhos desta linha. Desta forma supõe-se que tenha sido ele o mais recente responsável pelo despertar dos geomorfologistas em relação a esta abordagem. O fato concreto é que no IV Simpósio Internacional de Geomorfologia, ocorrido em Bologna, em 1997, uma seção sobre Magnitude-Freqüência foi aberta por causa do volume de trabalhos enviados naquela ocasião, inclusive os trabalhos acima referidos de COLÂNGELO e CRUZ (1997) e CROZIER e GLADE (1997), embora esta seção não tenha sido programada pela comissão organizadora.
Para que os leitores tenham uma idéia das possibilidades desta abordagem estatística, os dados apresentados nas Figs 1 e 2 nos indicam, para a área do Bairro do Cedro, no município de Paraibuna, que uma chuva de $60 \mathrm{~mm}$ tem uma expectativa de retorno de 1 ano. Indicam também que uma chuva de $14 \mathrm{~mm}$, que chamamos de dominante, contribui com $395 \mathrm{~mm}$ no total anual, 0 cume da curva da Fig 2, cuja média é de $1385 \mathrm{~mm}$ (observem os leitores que a chuva de $60 \mathrm{~mm}$ só contribui com $60 \mathrm{~mm}$ do total anual). Neste exemplo o escoamento superficial, runoff, foi também analisado com base numa estimativa média hipotética de $15 \mathrm{~mm}$ a serem subtraídos de cada evento de chuva, que se referem ao montante infiltrado e ao estoque de superfície.

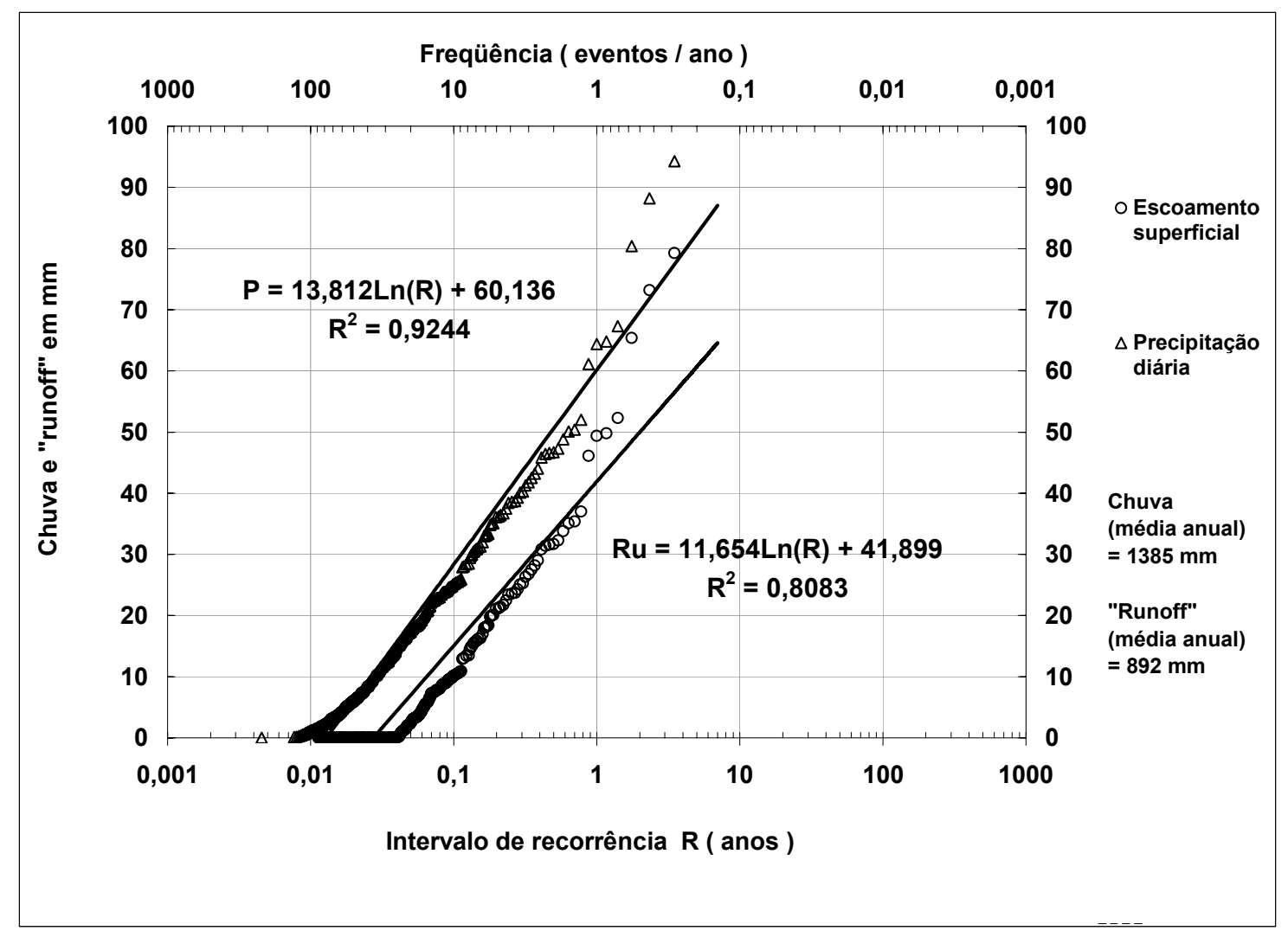

Figura 1 Bairro do Cedro, chuva e escoamento Superficial (runoff).

Observando os resultados apresentados na Fig 2, verifica-se que o evento de runoff de $14 \mathrm{~mm}$ é também um evento dominante, que contribui com $136 \mathrm{~mm}$ na média do total anual. Este fato está matematicamente demonstrado em DE PLOEY et al. (1991). Notem também que os intervalos de recorrência para eventos de runoff estão todos deslocados para a direita, e que a média do total anual é da ordem de $890 \mathrm{~mm}$.

A partir das análises descritas acima, adota-se um procedimento que difere daquele adotado por DE PLOEY et al. (1991). Adotamos o índice ou coeficiente de partículas de 0,5\% e um valor de $1,8 \mathrm{~g} / \mathrm{cm}^{3}$ para a densidade média das partículas dos agregados superficiais. Os resultados apontam para uma estimativa 
de evento dominante de erosão de $1300 \mathrm{~kg} / \mathrm{ha}$ o que produz 12.230 $\mathrm{kg} / \mathrm{ha}$ de material mobilizado, de modo que a integral da curva magnitude-freqüência $x$ intervalo de recorrência resulta em 92 ton/ha.ano.

Como referido acima, em 1997 fizemos, por analogia, uma transposição do conceito de freqüência temporal para freqüência espacial de ocorrência de eventos. Assim pudemos trabalhar com as magnitudes, em área, de movimentos de massa holocênicos do tipo slump, tendo sido mapeados os seus respectivos depósitos na área do Planalto do Paraitinga. Na Fig. 3 são apresentados os resultados obtidos na área amostral Bacia São Carlos, com apenas $2,0 \mathrm{~km}^{2}$. Um evento com extensão da ordem de $7700 \mathrm{~m}^{2}$ domina a distribuição de magnitudes e freqüências, sendo responsável pela produção de $37500 \mathrm{~m}^{2}$ de área de depósitos em $1 \mathrm{~km}^{2}$, ou seja, $3,8 \%$. A área total atingida por depósitos é da ordem de 331210 $\mathrm{m}^{2} / \mathrm{km}^{2}$, ou seja, $33 \%$ da área da bacia hidrográfica, cuja declividade média das vertentes obtida pelo método das "feições mínimas" é de 16 graus, portanto, com relevo do tipo serrano. Este exemplo ilustra bem as possibilidades desta abordagem para 0 prognóstico de ocorrência e a quantificação da susceptibilidade de ocorrência de processos deste tipo. Na segunda parte deste artigo, vamos tratar da evolução de alguns modelos físicos aplicados ao entendimento dos mecanismos envolvidos no desencadeamento de processos de movimentos de massa.

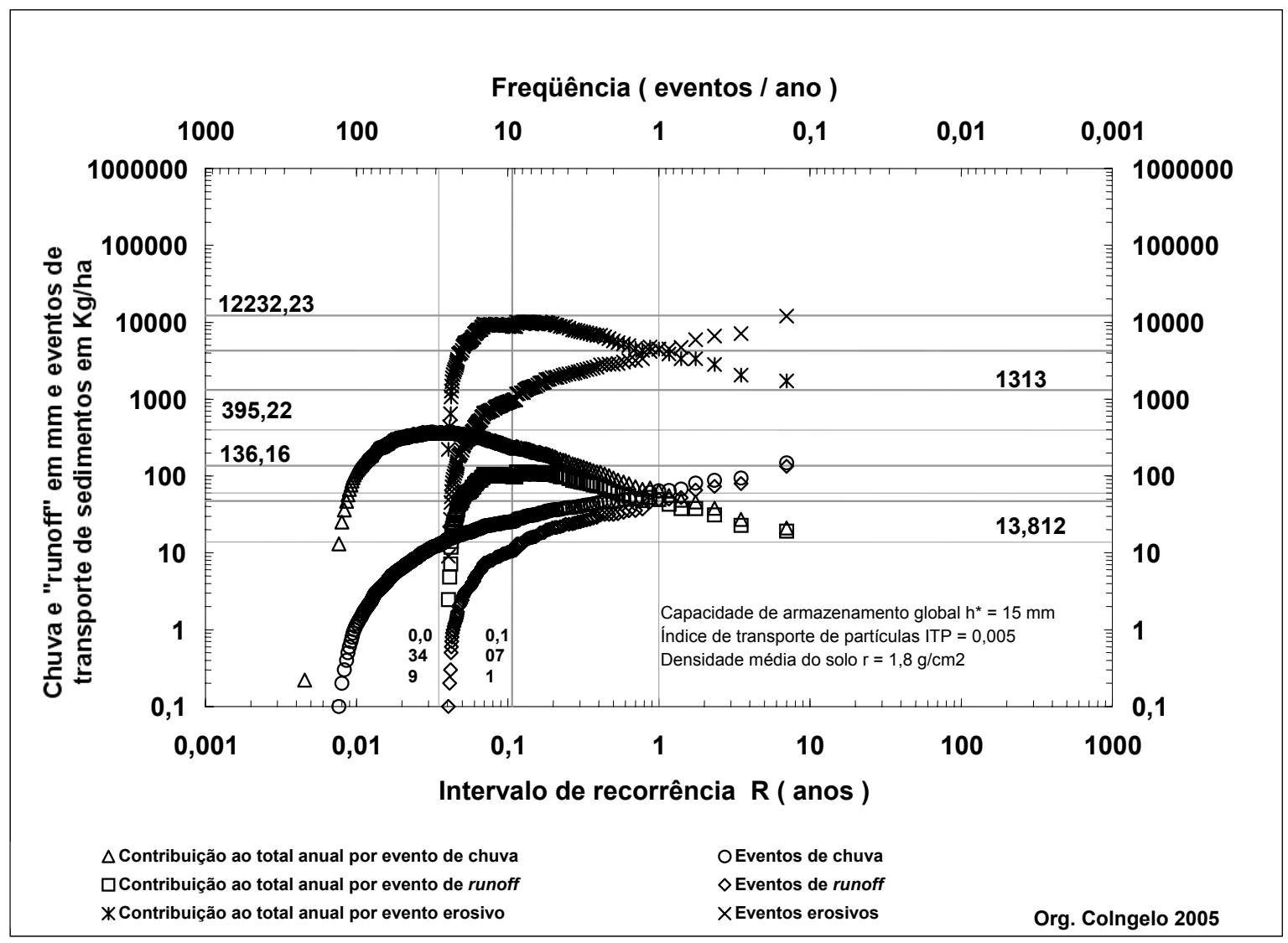

Figura 2 Bairro do Cedro - Magnitude e freqüência da chuva, escoamento superficial e material mobilizado.

\section{Os modelos da mecânica dos solos e a análise de estabilidade de vertentes}

Como preâmbulo à questão central deste artigo, vamos mostrar, de modo muito resumido, como evoluíram as concepções acerca da ocorrência de rupturas nos materiais terrígenos e os principais modelos propostos nos últimos 230 anos para descrever estes fenômenos que podem dar origem aos movimentos de massa. Pois bem, em 1776 COULOMB propõe a primeira equação que expressa a resistência ao cisalhamento nos seguintes termos:

$$
\tau=\mathrm{c}+\mathrm{s} \cdot \tan \mathrm{j}
$$


Nesta equação, a resistência ao cisalhamento do material $(\tau)$ é função da coesão (c), do ângulo de friç̧ão interna (j) e da tensão normal ao plano de ruptura potencial (s). Testes triaxiais em laboratório podem constatar que a maior parte dos materiais terrígenos apresentam, numa determinada faixa de tensões, um comportamento que se aproxima estatisticamente da função linear proposta por COULOMB em 1776.

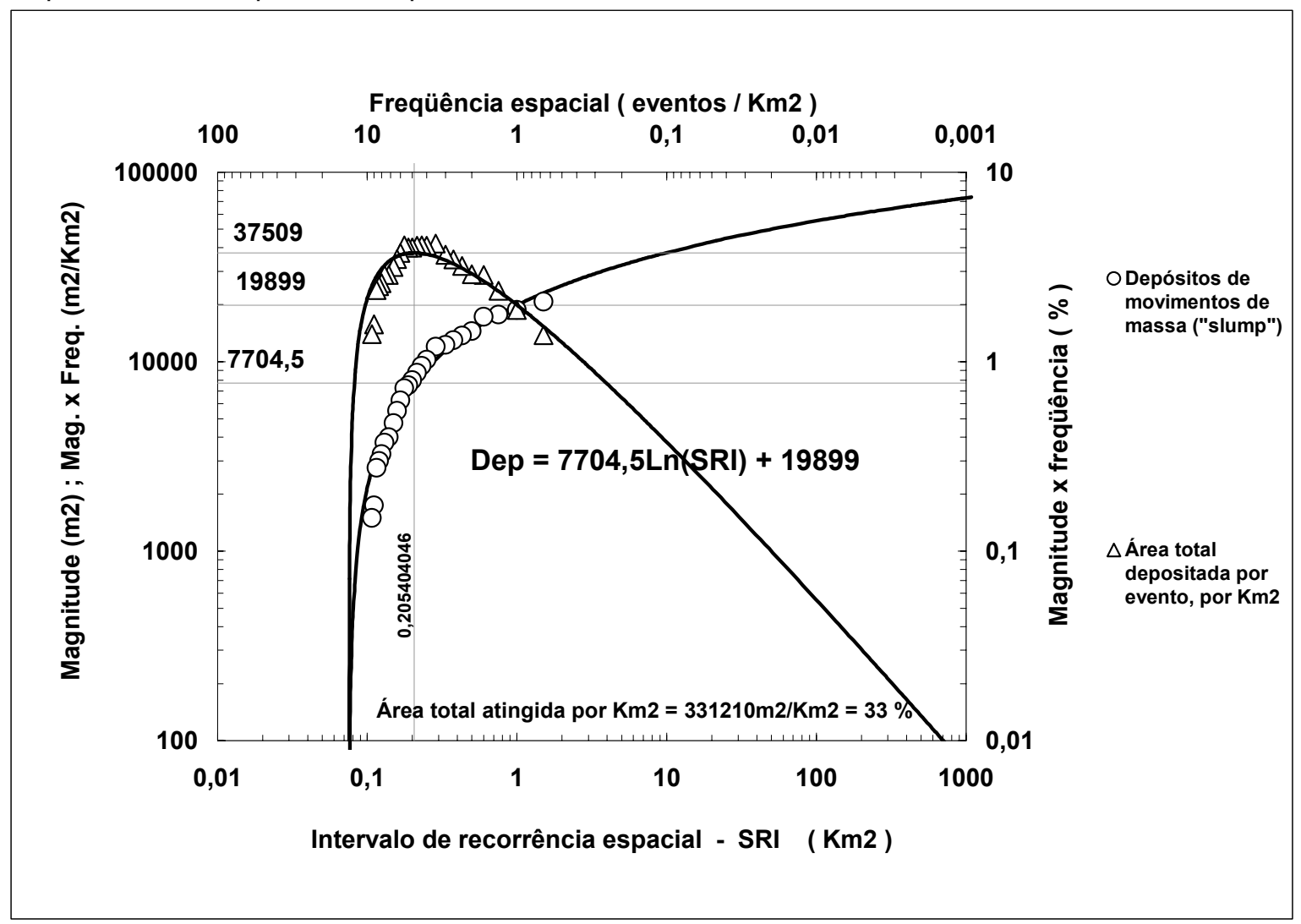

Figura 3 Magnitude e freqüência espacial dos depósitos de slump holocênicos da Bacia São Carlos, em embasamento formado por Micaxisto.

Como será visto nos parágrafos subseqüentes, a equação original proposta por COULOMB foi acrescida ao longo dos últimos 230 anos de outras variáveis sem que, entretanto, sua estrutura básica fosse refutada. A primeira modificação importante foi feita por TERZAGHI (1925, apud TERZAGHI, 1956) a partir de experimentos de laboratório. Eles mostraram que a resistência ao cisalhamento seria melhor expressa pela fórmula abaixo:

$$
\tau=\mathrm{c}+(\mathrm{s}-\mathrm{u}) \cdot \tan \mathrm{j}
$$

TERZAGHI (1956) acrescentou a tensão neutra da água (u) à fórmula original. Esta modificação no modelo de COULOMB não representou apenas um aprimoramento na descrição do fenômeno, mas conduziu à descoberta de que "u" não depende só das condições de carga aplicada, depende também da velocidade de sua aplicação. Este fato levou às noções de resistência lenta e rápida dos materiais, o que exigiu uma importante modificação nos ensaios laboratoriais. Sob certo aspecto, a hipótese de COULOMB parece ter sido enfraquecida pelos testes experimentais feitos por TERZAGHI (1956), porém a sua estrutura original não foi abalada, simplesmente um termo foi acrescentado. Um termo suficientemente importante para gerar o que chamamos de hipótese auxiliar: a tensão neutra da água depende da velocidade da carga aplicada. Por conseguinte, a resistência ao cisalhamento também. Esta alteração nos diz que não existe uma simples relação direta entre a tensão normal e 0 valor de carga local, mas depende também do teor de umidade presente no solo. Nestas condições, a tensão normal à superfície de ruptura potencial foi denominada tensão efetiva (effective stress), expressa na forma: 


$$
\mathrm{s}^{\prime}=(\mathrm{s}-\mathrm{u})
$$

Mais adiante, em 1936, HVORSLEV chamou a atenção para 0 fato de que a coesão das argilas saturadas não era uma constante como se pensava, mas dependia também do seu teor de umidade, c' $=\mathrm{f}(\mathrm{w})$, que passou a ser chamada de coesão efetiva (c'). Assim sendo, a equação original de COULOMB sofreu mais uma modificação, resultando então:

$$
\tau=\mathrm{f}(\mathrm{w})+(\mathrm{s}-\mathrm{u}) \cdot \tan \mathrm{j}
$$

Este aparente pequeno acréscimo feito por HVORSLEV, levou a outra descoberta. A de que devemos distinguir entre argilas normalmente consolidadas, para as quais a equação linear é satisfatória, de argilas pré-consolidadas cujo comportamento da resistência não é linear.

A estrutura original exibida pela equação de COULOMB resistiu ao tempo, tendo sido aprimorada com a introdução de uma variável, as condições de umidade do solo atuando sobre a tensão normal (TERZAGHI) e a coesão efetiva (HVORSLEV). Por muito tempo nas análises do limite de equilíbrio aplicadas à estabilidade das encostas naturais, os limiares de ruptura foram supostos unicamente para a condição de saturação total dos materiais, seja considerando o "modelo de vertente infinita", para as superfícies de ruptura planares, sejam os métodos das fatias de FELLENIUS ou de BISHOP, para as superfícies de ruptura circulares.

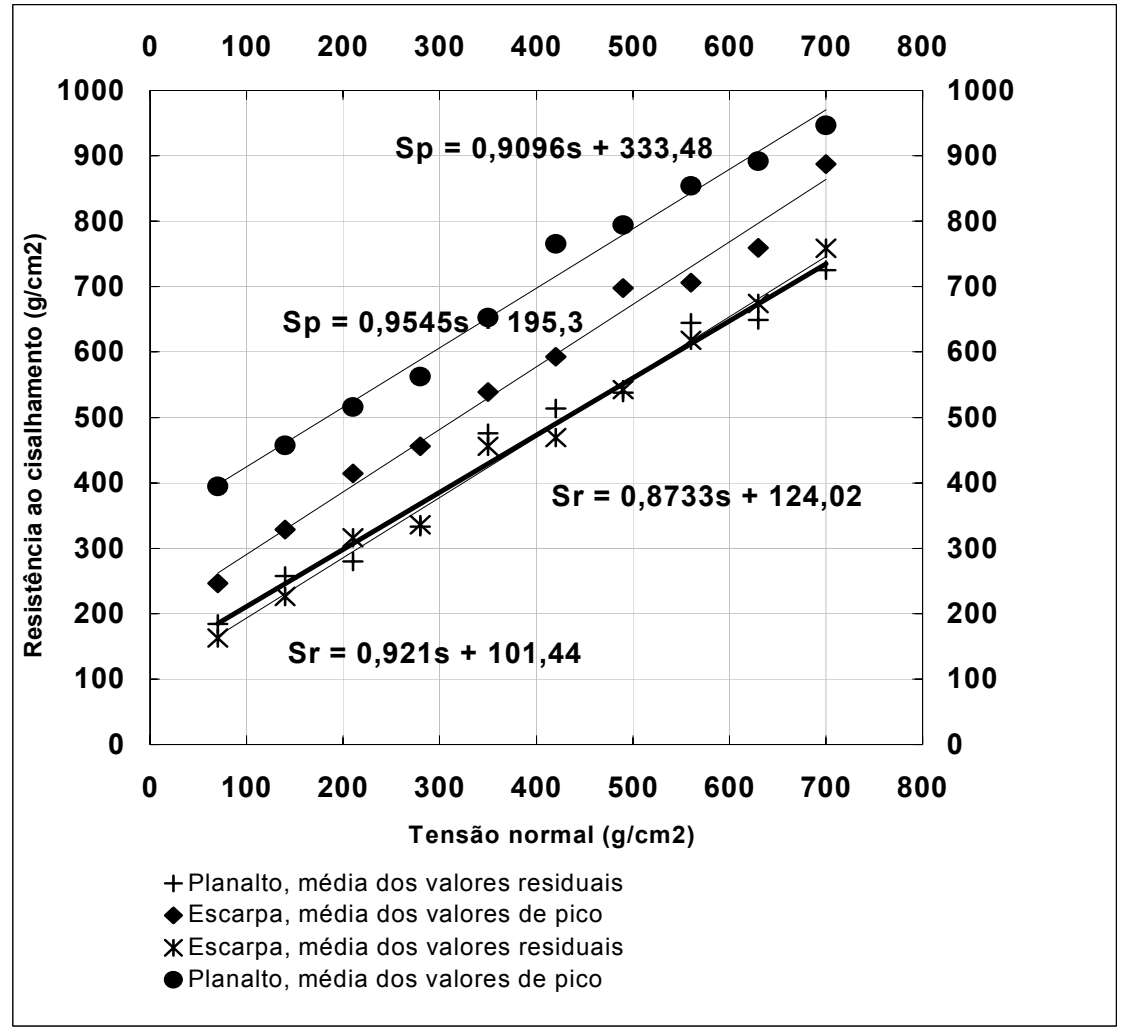

Figura 4 Resistência ao cisalhamento. Média dos valores de pico e residuais para os materiais superficiais no Planalto de Paraitinga e na Escarpa da Serra do Mar.

Foi só por volta de 1950 que BISHOP deu início aos testes em solos não saturados (BISHOP et al. 1960, apud FREDLUND, 1987). Segundo relata FREDLUND, foram os primeiros testes a monitorar de modo independente as pressões poro-ar (ua) e poroágua (uw), porém sem obter resultados satisfatórios do ponto de vista experimental e da sua aplicação. No entanto, foi apenas em 1977 que FREDLUND e MORGENSTERN conseguiram resolver 0 problema, incluindo a variável "sucção matricial" na fórmula original de COULOMB-TERZAGHI, com uma modificação no critério de ruptura do envoltório de Mohr-Coulomb (FREDLUND et al, 1978). 
Desta forma obtiveram uma expressão adequada das variáveis envolvidas, incorporando agora a condição de tensão de solo não saturado. Nas equações 5 e 6 abaixo, a sucção matricial (ua - uw) é responsável por incrementos no intercepto de coesão:

$$
\begin{aligned}
& \tau=c^{\prime}+(\text { sn }-u a) \tan j^{\prime}+(u a-u w) \tan j b \\
& c=c^{\prime}+(u a-u w) \tan j b
\end{aligned}
$$

Na equação 5 sn corresponde à tensão normal total. Os incrementos coesivos devido à sucção matricial no método de FREDLUND estão expressos nas equações 5 e 6 pelo ângulo jb, que representa a taxa de incremento da resistência ao cisalhamento em função do aumento da coesão, resultante do acréscimo nos valores da sucção matricial. 0 método de FREDLUND tem tido muita aceitação, sendo referência teórica nos trabalhos de autores, tais como M. G. ANDERSON, S. M. BROOKS, M. J. KEMP e outros.

Admitida a hipótese auxiliar que supõe a existência de tensões de sucção matricial suficientemente fortes para incrementar a coesão em valores relevantes e, portanto, também a resistência ao cisalhamento, há que supor que tais tensões possam produzir incrementos de resistência capazes de elevar o fator de segurança acima da unidade, numa encosta ou setor de encosta objeto de análise.

BROOKS et al. (1999), ao tratarem da modelização da estabilidade de encostas no Holoceno apontam para o problema da parametrização e validação de um modelo deste gênero porque, conforme estes autores, a existência de superfície de ruptura, condição necessária para a validação do modelo, simplesmente elimina a possibilidade de parametrização do modelo. Estes autores acrescentam ainda que a existência de condições apropriadas para a parametrização geométrica, geotécnica e hidrológica só é possivel em encostas que ainda não sofreram deslizamentos de terra. Daí a importância da utilização de modelos físicos aplicados ao estudo da estabilidade de encostas nas condições atuais.

Foi visto acima como historicamente pode evoluir um modelo ou teoria, no caso, a aplicação da teoria da plasticidade, subcampo da reologia, ao problema do cisalhamento dos materiais terrígenos. Desta história, fica claro que o caminho iniciado por COULOMB em 1776 era frutífero, tanto que, como já foi dito, a estrutura fundamental de seu modelo nunca foi abalada. Quer dizer, a resistência ao cisalhamento dos materiais terrígenos é fundamentalmente função da coesão eletroquímica, devido aos colóides, e do ângulo de fricção interna, cuja contribuição maior é devido ao material mais grosseiro. Estas duas variáveis continuam sendo indiscutivelmente as variáveis independentes fundamentais no equacionamento do problema da resistência ao cisalhamento do solo. Entretanto, elas mesmas são variáveis dependentes em relação a outras variáveis, as quais são independentes nos submodelos, ou hipóteses auxiliares, que as correlacionam.

\section{Os mecanismos de auto-regulação e 0 jogo de tensões de resistência e de cisalhamento}

As encostas dos maciços, morros e colinas nos planaltos, nas escarpas, bem como as planícies correspondem a sistemas de formas do relevo, os quais podem ser descritos em função de suas características morfológicas, morfométricas e topográficas. As formas de relevo podem ser convexas, retilíneas ou côncavas, nas projeções em planta e em perfil, resultando assim em nove tipos básicos de formas (RUHE, 1975). Pode-se atribuir a cada um desses tipos um status geo-ecológico distinto, o que fica patente quando confrontamos as formas "policonvexas" e "policôncavas", porque são antagônicas, não apenas do ponto de vista geométrico, mas também da hidrodinâmica de superfície e de subsuperfície, dos processos pedo-geoquímicos dominantes, das formações superficiais e solos, da composição florística da cobertura vegetal e também com relação aos fatores microclimáticos (COLÂNGELO, 1995a, 1996b). GREGORY (1978) apresenta uma equação, também adotada, entre outros, por DERBYSHIRE et al. (1979), onde a forma do relevo ( $\mathrm{F}$ ) aparece como uma variável dependente dos processos $(\mathrm{P})$ e dos materiais $(\mathrm{M})$ no tempo, conforme a expressão: $\mathrm{F}=(\mathrm{P}, \mathrm{M}) \mathrm{dt}$.

A dinâmica das encostas é comandada por um jogo de tensões que interage diretamente com os processos geomórficos. Há um permanente confronto entre as tensões passivas, de sustentação dos materiais superficiais não consolidados, e as tensões ativas de cisalhamento. Todo e qualquer processo é desencadeado a partir da superação de tensões passivas por tensões ativas solicitantes, ou seja, quando um determinado valor limiar for atingido. Os materiais superficiais são inconsistentes, ou seja, são constituídos por partículas individuais sustentadas por coesão eletroquímica proveniente dos colóides do solo, principalmente das argilas e matéria orgânica, e por atrito, ou fricção interna, associado em sua maior parte à fração arenosa $\mathrm{e}$ granular. Obviamente, uma série de fatores intervêm sobre estas variáveis, ora favorecendo a tensão de resistência ao cisalhamento, ora favorecendo a tensão cisalhante. Intensa pluviosidade e conseqüente escoamento superficial e hipodérmico promovem periodicamente a queda da resistência dos materiais superficiais, 
suporte do sistema geomórfico. 0 abatimento da resistência pode chegar a níveis extremos, atingindo valores críticos, abaixo dos limiares, podendo, neste caso, gerar superfícies de ruptura com desencadeamento de movimentos de massa. Os escorregamentos correspondem a uma resposta desses sistemas à convergência de inúmeros fatores, representando a busca por um novo perfil de equilíbrio para a encosta. Sem dúvida, o estudo destes processos em meio tropical úmido deve enfatizar a participação do escoamento subsuperficial. $\mathrm{Em}$ áreas tropicais úmidas, tectonicamente estáveis, ou seja, de baixo risco sísmico, a água é 0 grande fator de dinamização das encostas. Assim como 0 escoamento superficial (pluvial e fluvial), 0 escoamento subsuperficial é, em grande parte, controlado pela magnitude, frequeência, intensidade e duração dos eventos pluviométricos. Sua qualidade e, secundariamente, sua quantidade são controladas pela morfologia do terreno, estrutura litotectônica, profundidade, textura, estrutura e composição do material superficial, incluídos os horizontes de solo, quantidade e qualidade da matéria orgânica humificada, atividade biológica, tipo de sistema radicular e estrutura da porção subaérea da vegetação. A grande quantidade de fatores e variáveis envolvidos nos mecanismos dos processos corresponde a um grande obstáculo nas tentativas de prognóstico. Deste fato decorre a importância da aplicação de modelos nestes estudos, principalmente os modelos físicos. Se com eles o grau de incerteza é elevado, sem eles, o prognóstico se torna incomensurável.

Um problema central que persiste no uso de modelos matemáticos em Geomorfologia Processual, assim como em outros campos da Geografia Física, é a questão de sua "validação". Validar um modelo é o mesmo que validar uma hipótese central. No campo da Matemática Pura a validação consiste no teste da consistência interna das proposições feitas com base num sistema de relações de um conjunto de axiomas fundamentais considerados. Já, nos modelos matemáticos aplicados ao estudo de objetos reais com 0 intento de se obter predições, o problema é muito diferente. Uma variável dependente é apresentada como função de um certo número de variáveis independentes, correlacionadas segundo um determinado algorítmo, tanto mais complexo quanto maior o número de variáveis consideradas. Por exemplo, no estudo de processos geomórficos aplica-se modelos provenientes de outras áreas do conhecimento, tais como os da Mecânica dos Fluidos, os da Mecânica dos Solos, assim como os da Geoquímica, com a finalidade de melhorar 0 entendimento sobre a dinâmica e a evolução das vertentes naturais. Neste caso, 0 principal problema reside no fato de não ser possível, até 0 momento, reproduzir experimentalmente em laboratório uma vertente com todos os seus elementos fundamentais, para poder então controlar as variáveis desejadas, e com mínima intervenção sobre o sistema estudado.

Entretanto, apesar de não ser possível reproduzir em laboratório mais que pequenas partes do sistema em estudo, e de serem as condições bastante artificiais, 0 controle sobre as variáveis testadas é muito maior que 0 obtido em experimentos de campo. Nos experimentos de campo ocorre 0 oposto, o controle sobre as variáveis é precário, mas o sistema está mais próximo das condições naturais, ou originais. Mesmo com todas as dificuldades, os resultados obtidos a partir de experimentos de campo e laboratório em Geomorfologia conduziram a grandes avanços nesta área nos últimos trinta anos.

TEMPLE e RAPP (1972) afirmaram que chuvas intensas podem causar movimentos rápidos, os quais, em condições normais, levariam de 25 a 50 anos para ocorrer. DE PLOEY e GABRIELS (1980) referem-se às corridas de lama, por ocasião de fortes chuvas, como conseqüência de rápido decréscimo do índice de fricção interna aparente (tan j') que leva a liqüefação do material. Para CARSON e KIRKBY (1972), os escorregamentos são "(...) uma expressão dramática da tensão cisalhante sobre a resistência dos materiais na encosta (...)". Favorecer a resistência ao cisalhamento é o papel desempenhado pela tensão normal ao plano de cisalhamento, porque ela mobiliza, ou seja, torna efetivo 0 atrito, que é propriedade intrínseca dos materiais. 0 atrito se manifesta em termos de um aumento da resistência ao cisalhamento proporcional ao aumento da tensão normal, numa razão que é definida pela tangente do ângulo de fricção interna aparente. Assim, podemos entender que embora seja 0 atrito interno uma característica intrínseca do material, sua manifestação depende da aplicação de tensão externa cisalhante.

No caso da ocorrência de escorregamentos em encostas escarpadas de perfis retilíneos, onde a superfície de ruptura pode ser considerada paralela à superfície do terreno, com profundidade muito menor (de $1 \mathrm{~m}$ a $3 \mathrm{~m}$ ) que 0 comprimento da encosta (de 100 $\mathrm{m}$ a $600 \mathrm{~m}$ ), é freqüentemente utilizado "o modelo de vertente infinita". CHOWDHURY (1978), ao aplicar a "análise do limite de equilíbrio" na avaliação da estabilidade de encostas, separa o corpo relativamente estático do solo do corpo dinâmico que constitui a água de percolação. 0 autor supõe também em sua análise, quatro situações hidrodinâmicas bem definidas: solo submerso, solo totalmente drenado, solo parcialmente saturado com fluxo paralelo à superfície e solo totalmente saturado com fluxo paralelo e atingindo a superfície. Além disso, cumpre salientar a importância que representa para esta análise a sobrecarga adicional referente a 
cobertura vegetal, tratada em pormenores por SIDLE et al. (1985). Embora estes autores considerem 0 aumento de coesão (DC) representado pelo sistema radicular da cobertura florestal, não levam em consideração o favorecimento da percolação da água por acréscimo da condutividade hidráulica do solo (K) promovido por micro-raízes, raízes mortas e mesmo a matéria orgânica em decomposição (DE PLOEY e CRUZ, 1979). Estaria assim a cobertura florestal promovendo um aumento da instabilidade do terreno, em função de uma maior percolação da água promovida pelo sistema de raízes. Sob este aspecto, também DE PLOEY (1981) refere-se aos efeitos contrários ambivalentes de alguns fatores erosivos, através de um grande número de exemplos, dentre os quais, 0 referente a um tipo específico de matéria orgânica que estaria, ao contrário das expectativas, dificultando a infiltração da água no solo, favorecendo assim 0 escoamento superficial.

\section{Limiares de declividade}

Ao ser estabelecida uma razão entre a tensão de resistência (S) e a tensão cisalhante (t), haverá condições de determinar uma análise de estabilidade de encostas. Na aplicação desta análise, um dos objetivos deste trabalho é estabelecer os limiares de declividade para a condição de estabilidade, devendo ser consideradas as propriedades dos materiais superficiais não consolidados de alteração e solo, bem como os materiais coluviais. Para isso, deve-se conhecer, conforme VARGAS (1970), a textura, porosidade, índice de vazios, teor de umidade, condições de saturação dos materiais e índice de atividade mecânica. Os limiares de declividade, empiricamente estabelecidos por CRUZ (1975) para áreas escarpadas, como na Serra de Caraguatatuba, situam-se em torno do valor de $22^{\circ}$ ou $40 \%$, obtidos a partir da relação entre mapa de declividades e o mapeamento dos escorregamentos. Tais resultados se aproximam destes aqui apresentados, obtidos com os ensaios de cisalhamento feitos posteriormente (década de 80). Nas áreas planálticas de morros e serras de Paraibuna e Paraitinga, os limiares de declividade, obtidos dos ensaios rápidos de campo aplicados à "análise de limite de equilíbrio" (COLÂNGELO, 1990, 1995a e 1996a), indicam valores de $18^{\circ}, 20^{\circ}$ e $22^{\circ}$, respectivamente para encostas sobre embasamentos rochosos de Micaxisto, Migmatito e Granito-Gnaisse.

Outro objetivo deste trabalho é confrontar os resultados obtidos, a partir da aplicação da análise dos limiares de declividade, dos materiais superficiais das baixas encostas escarpadas da Serra de Caraguatatuba com os do seu reverso planáltico da área de Paraibuna. Neste sentido, são levados em conta os condicionantes topogeomórficos, as características mecânicas dos materiais e a hidrodinâmica de superfície das duas áreas referenciadas.

\section{Movimentos de Massa e Experimentação}

Muito se tem estudado a respeito dos processos que dinamizam as encostas para entender seus mecanismos de gênese e evolução, através de recursos experimentais ou de medição, ou ainda, como resultado de pura observação. Um experimento tem por objetivo testar um par de variáveis, sob controle das demais, na tentativa de obter-se um possível algorítmo que as una, e poder assim fazer além de diagnósticos, também prognósticos. A partir dos ensaios rápidos de campo, realizados com 0 aparelho sheargraph, em materiais de alteração e de colúvios (Fig. 2), são medidos os parâmetros coesão e os ângulos de fricção interna aparentes. Para isto é realizado um experimento, onde o material é levado à ruptura a partir da aplicação de uma tensão cisalhante para um nível de tensão normal conhecido. 0 experimento é repetido para dez níveis distintos de tensão normal de modo que, a partir de regressão linear simples, obtém-se a curva da resistência ao cisalhamento. Uma curva que representa 0 envoltório de resistência de MOHR-COULOMB.

Com a aplicação dos resultados deste experimento na análise de limite de equilíbrio, e com base no modelo de vertente infinita, é possível determinar os limiares de declividade das encostas, a partir dos quais passa a haver risco iminente de ocorrência de escorregamentos. Nesta análise, é possível avaliar as diferentes condições de estabilidade e seus limiares de declividade, para distintas situações de drenagem interna dos materiais. Interessa sobremaneira supor estar 0 material na iminência de sofrer ruptura, portanto a coesão deve estar próxima de zero, sendo neste caso de valor desprezível (SKEMPTON e DELORY, 1957 apud CARSON, 1975). Um detalhamento sobre o método adotado pode ser encontrado em COLÂNGELO (1995b e 1996a).

Conforme DE PLOEY, CRUZ e MODENESI (1978), o limiar de declividade do terreno para a condição de equilíbrio limite, considerados os pressupostos acima referidos e um fluxo paralelo à superfície percolando os materiais superficiais da encosta, é dado por:

$b l=\arctan \left\{(1-m \cdot g w / g s) \tan j^{\top}\right\}$,

donde:

bl: limiar de declividade

m: posição relativa ao nível de saturação 


$$
\begin{aligned}
& \text { ( } m=1 \text {, saturação completa; } m=0 \text {, material totalmente drenado) } \\
& \text { gw: peso específico da água } \\
& \text { gs: peso específico do solo úmido } \\
& \text { j': ângulo de fricção interna aparente } \\
& \text { tan j’: índice de fricção aparente }
\end{aligned}
$$

Nas encostas escarpadas da serra de Caraguatatuba, muitos ensaios foram efetuados durante a década de oitenta, em pontos acessíveis e disponíveis, escolhidos em função dos materiais coluviais e de alteração, sendo realizados preferencialmente nos horizontes $\mathrm{B}$ dos solos. Os horizontes $\mathrm{C}$, quando sua alteração se apresentava incipiente, com grande quantidade de partículas maiores que $4 \mathrm{~mm}$, não permitiam em geral a realização dos testes. No Planalto de Paraibuna e Paraitinga, os ensaios vêm sendo efetuados até os dias atuais. Certamente o material ótimo para a execução dos testes é aquele que se apresenta muito pobremente selecionado, com mais de $30 \%$ de finos (silte, argilas e ferro) e com uma certa percentagem de umidade próxima ao limite de plasticidade. Daí a freqüente necessidade de se proceder a um umidecimento artificial do material, quando este se apresentar muito ressecado.

\section{Discussão e Resultados}

Dentre os múltiplos ensaios, foram selecionados os referentes aos materiais superficiais nas faces leste e norte das baixas e médias encostas do morro do Tinga, nas escarpas de Caraguatatuba, em migmatitos oftálmicos. Foram então confrontados com os materiais coluviais de taludes ou leques detríticos na planície do rio Santo Antônio, formados por ocasião dos escorregamentos de 1967, e aos referentes ao planalto de Paraibuna. As curvas de regressão linear simples expressam os limiares de pico e residuais da resistência ao cisalhamento. Neste trabalho, porém, foram apenas considerados os valores de pico. As curvas demonstram um comportamento diferenciado da resistência ao cisalhamento pela coesão de ângulo de atrito, em função da composição textural e estrutural dos materiais nos contatos entre os horizontes e entre 0 material de alteração e 0 coluvial. Foram feitos os ensaios geralmente nos cortes de baixas e médias encostas, coletadas amostras retiradas do cabeçote do sheargraph e dos perfis de solo para exame granulométrico e determinação dos limites de liquidez e plasticidade de Atterberg.

As curvas referentes aos materiais da face leste de um dos interflúvios do morro do Tinga mostram sua maior resistência ao cisalhamento, tanto pela componente coesão como pelo atrito. A maior coesão pode ser atribuída à grande quantidade de sedimentos finos (72\%, na maior parte argilas) no ponto $\mathrm{n} .1$ de topo de interflúvio (Fig. 5). Os maiores ângulos de atrito na face leste $\left(45^{\circ}\right.$ e $\left.48,5^{\circ}\right)$ devem estar associados a presença de uma certa quantidade de grânulos. Nesta face leste, quase voltada para 0 mar, o material de alteração apresenta uma coesão maior (180 $\mathrm{g} / \mathrm{cm}^{2}$ ) se comparado com 0 da face norte, que apresenta coesão de $40 \mathrm{~g} / \mathrm{cm}^{2}$. Tal fato seria explicado pela maior profundidade dos ensaios na face leste realizados a 7 metros e por serem mais argilosos; na face norte, foram menos profundos (5 metros), portanto, mais alterados. Nas duas faces, os materiais coluviais são mais coesos $\left(340\right.$ e $\left.250 \mathrm{~g} / \mathrm{cm}^{2}\right)$ que os de alteração, mas apresentam menores ângulos de atrito $\left(40 \mathrm{e} 45^{\circ}\right)$. Isto se deve à maior quantidade de fração arenosa ( $49 \%$ e $52 \%$ ) do que nos de alteração. Os ensaios realizados na face norte apresentam valores aproximados, com a menor coesão, certamente pela presença de maior quantidade de areia.

Diante do exposto, pode-se crer na possibilidade de haver um mecanismo de compensação quanto aos escorregamentos, garantindo uma relativa estabilidade nas encostas escarpadas, mesmo sob intervenção dos agentes já referidos, sendo a resistência ao cisalhamento equivalente em quantidade nos dois tipos de material, embora diferente do ponto de vista qualitativo (COLÂNGELO, 1995, 1996). Isto é, o material de alteração oferece menor coesão, porém maiores valores de ângulo de atrito, enquanto que o material coluvial possui maior coesão e menores ângulos de atrito, controlados pela magnitude e freqüência de eventos pluviométricos.

Dois dos ensaios realizados em taludes ou leques detríticos, depositados pelos escorregamentos de 1967, mostram serem esses depósitos menos resistentes ao cisalhamento que os coluviais das encostas acima consideradas: sua recente deposição é certamente responsável por sua menor coesão. 0 ponto n.6 (Fig. 5) apresenta $180 \mathrm{~g} / \mathrm{cm}^{2}$ de coesão e elevada quantidade de areia $(66,69 \%)$, devendo ser esta última relacionada ao ângulo de atrito de $45,5^{\circ}$, bem maior que 0 do ponto n.5 (Fig. 5), com $35^{\circ}$ e menor quantidade de areia. É que a resistência ao cisalhamento nos taludes detríticos atuais vincula-se fortemente à composição textural, diferenciada em função da localização dos ensaios. De acordo com as distâncias de deposição entre as baixas encostas e a parte distal desses taludes, os materiais menos grosseiros tendem a se distanciar e a se espalhar na planície.

No vale do rio Pardo no planalto de Paraibuna, ainda em migmatitos oftálmicos, os materiais coluviais apresentam-se mais resistentes ao cisalhamento pela coesão muito elevada $\left(570 \mathrm{~g} / \mathrm{cm}^{2}\right)$, porém com ângulo de atrito $\left(35^{\circ}\right)$ inferior aos das encostas do 
Tinga, sob maiores condições de umidade. 0 material de alteração, por sua vez, apresenta bem menor coesão, mas com ângulo de atrito mais elevado $\left(200 \mathrm{~g} / \mathrm{cm}^{2}\right.$ e $\left.41^{\circ}\right)$. No planalto, os materiais apresentam-se mais coesos que os materiais nas escarpas de Caraguatatuba. Isto se deve principalmente a uma elevação nos teores de argila. Por outro lado, assim como ocorre nas escarpas, os materiais mais superficiais em geral são mais coesos que em profundidade. Tais materiais correspondem geralmente aos horizontes B dos solos, sendo mais argilosos que os materiais de alteração mais profundos, podendo haver sido também desenvolvidos em colúvios (Fig. 4). Embora menos argilosos, foi inferido que os tipos de argila presentes nos materiais das alteritas são mecanicamente mais ativos, o que deve compensar, em parte, no que se refere à estabilidade da encosta, uma descontinuidade textural, a qual sob outras circunstâncias, poria estes materiais na condição de risco iminente de sofrer colapso coesivo, mesmo em condições pluviométricas habituais (COLÂNGELO, 1995b).

Quanto aos limiares de declividade para estabilidade de encosta, considerando a ocorrência de eventos pluviométricos extremos com saturação completa dos materiais superficiais, é importante salientar que, enquanto nas escarpas foram encontrados valores entre $20^{\circ}$ e $29^{\circ}$, no planalto de Paraibuna eles ficaram compreendidos entre $24^{\circ}$ e $28^{\circ}$. Isto significa que áreas de alto risco, nas encostas da serra de Caraguatatuba, podem ser encontradas a partir do limiar de $20^{\circ}$ de declividade do terreno $\left(22^{\circ}\right.$ em CRUZ, 1975), enquanto que, no planalto, as condições de risco iminente poderão ser observadas quando a declividade for superior a $24^{\circ}$. Por outro lado, 0 teto dos limiares de declividade nos dois sistemas de relevo apresentam-se bastante próximos $\left(29^{\circ} \mathrm{e} 28^{\circ}\right), 0$ que pode estar relacionado a um fator limitante imposto por parâmetros climáticos. Esta é uma hipótese que está sendo testada por COLÂNGELO.

Fatores importantes como pluviosidade, fluxo superficial e subsuperficial, raízes e declividade ajudam a entender as diferenças entre a dinâmica geomórfica nas escarpas e no planalto. As escarpas apresentam declives abruptos e são muito atingidas por freqüentes e intensas chuvas, 0 que favorece 0 comportamento mecânico e a descida dos materiais superficiais por movimentos de massa, com menor coesão no caso dos migmatitos oftálmicos granulares-arenosos. São necessários altos índices de atrito para que os materiais não se movimentem. Com grande quantidade $\mathrm{e}$ alta intensidade pluviométrica e predominância de fortes declividades, as escarpas da serra de Caraguatatuba tornam-se permanentemente áreas de risco, mesmo recobertas pela mata do parque florestal.
No planalto, notamos que os teores de argila e os índices de plasticidade são maiores para os materiais de horizontes $\mathrm{B}$, quando comparados aos de horizontes $\mathrm{C}$, o que está de acordo com os elevados índices argila/silte observados naqueles horizontes. Quanto aos limiares de declividade, ao confrontarmos os resultados obtidos para as escarpas da serra e o planalto, observamos que há uma inversão: enquanto nas escarpas os materiais de horizontes $B$, na condição de saturação completa, apresentam limiares mais baixos $\left(27^{\circ}, 23^{\circ}, 20^{\circ}\right)$ que os de horizontes $C\left(29^{\circ}, 27^{\circ}, 27^{\circ}\right)$, no planalto os seus valores são geralmente mais altos $\left(27^{\circ}, 27^{\circ}, 24^{\circ}\right)$ que os apresentados pelos horizontes $C\left(24^{\circ}, 26^{\circ}, 28^{\circ}\right)$. Estes valores mais elevados nos limiares de declividade das alteritas em relação aos horizontes B nas escarpas da serra, são devidos aos elevados teores de areia e grânulos $(48 \%, 52 \%, 67 \%)$ nelas encontrados, os quais são bastante mais baixos nas alteritas do planalto $(27 \%, 46 \%, 43 \%)$. Isto está de acordo com as condições extremas de declividade e pluviosidade encontradas nas escarpas da serra. Entretanto, as argilas que compõem os horizontes $C$ são sempre mecanicamente mais ativas, como 0 já referido em relação às escarpas da serra de Caraguatatuba. No planalto, os resultados apresentados por COLÂNGELO (1995), $18^{\circ}, 20^{\circ}$ e $22^{\circ}$, foram obtidos a partir das curvas da função ângulo de fricção interna aparente e teor de umidade para as alteritas em micaxistos, migmatitos e granitos e pela subseqüente plotagem dos valores dos limites de plasticidade nestas curvas, de modo a se obter os respectivos ângulos de fricção. Então, a partir da aplicação da "análise de limite de equilíbrio", combinada ao "modelo de vertente infinita" sobre estes ângulos de atrito, 0 autor chegou aos valores dos limiares de declividade acima referidos. Com a aplicação desta metodologia, os limiares de declividade são mais baixos que os apresentados pelo método tradicional. A validade desta metodologia ainda está sendo testada a partir do confronto com os casos emergentes, nas áreas de estudo.

Sabe-se que boa parte dos escorregamentos, principalmente os do tipo planar, em áreas tropicais úmidas escarpadas, têm suas superfícies de ruptura no contato entre os horizontes $B$ e a rocha alterada (CRUZ, 1974 e 1975; DE PLOEY e CRUZ, 1979), pelas fortes descontinuidades de caráter mecânico, textural e estrutural, existentes na passagem entre os citados horizontes. Por esta razão foram feitos nestes horizontes os ensaios de resistência ao cisalhamento, bem como a coleta de amostras para os ensaios de granulometria e limites de Atterberg (liqüidez e plasticidade).

Cumpre relembrar que os resultados obtidos por CRUZ (1975), a partir da superposição da carta de declividades com 0 mapa dos escorregamentos de 1967 , estão muito próximos $\left(22^{\circ}\right.$ ou 
$40 \%$ ) dos obtidos com os ensaios de campo. Do ponto de vista textural, todos os materiais apresentaram-se muito pobremente selecionados, com teores de areia entre $27 \%$ e $67 \%$, silte entre $4 \%$ e $34 \%$ e argila entre $14 \%$ e $66 \%$. Os horizontes B sempre se apresentam mais ricos em argila quando comparados com os horizontes C, embora os teores de finos (silte + argila + ferro) sejam equivalentes. Aplicando 0 índice argila/silte, observa-se também uma relação direta e proporcional entre este índice, a coesão do material e a proporção da redução do ângulo de atrito em função de um dado aumento, seja no teor de umidade, seja no teor de finos. Cumpre ressaltar também que, embora menos argilosos, os materiais de horizontes $C$ possuem tipos de argilas com maior atividade física e química, como no caso das vermiculitas ou das montmorilonitas (COLÂNGELO, 1990, 1995b), o que compensa, em parte, os baixos montantes de argila.

Os materiais referentes à área do Planalto apresentam-se, em geral, mais resistentes ao cisalhamento, principalmente quanto a coesão, graças aos horizontes B coluviais bastante argilosos. A grande incidência de escorregamentos nas escarpas da serra de Caraguatatuba deve-se a uma convergência de fatores, dos quais devemos ressaltar: maior umidade, pluviosidade, energia dos fluxos hídricos, de superfície e de subsuperfície, e calor na área da Serra de Caraguatatuba, além do embasamento rochoso formado por migmatitos oftálmicos, os quais apresentam, como produto de alteração, material muito pouco consistente (arena). Neste confronto de unidades de relevo, devemos lembrar que as diferenças morfológicas, por condicionarem os fluxos de superfície e subsuperfície, e também o comportamento da declividade das encostas e o tipo de superfície de escoamento a jusante, condicionam também, em boa parte, a textura, estrutura e composição dos materiais superficiais não consolidados $e$, conseqüentemente 0 comportamento mecânico destes materiais (COLÂNGELO, 1995). Nas encostas escarpadas fortemente retilinizadas, com perfis de horizonte $B$ pouco profundos $(1 \mathrm{~m})$, os escorregamentos são translacionais, paralelos à superfície do terreno. Quando o relevo é "mamelonado" fortemente convexizado, com perfis de solo mais profundos ( $>2 \mathrm{~m}$ ), os escorregamentos são rotacionais, sendo as superfícies de ruptura conchoidais. Portanto, os modelos a aplicar em cada caso devem contemplar a morfologia do sistema geomórfico em questão.

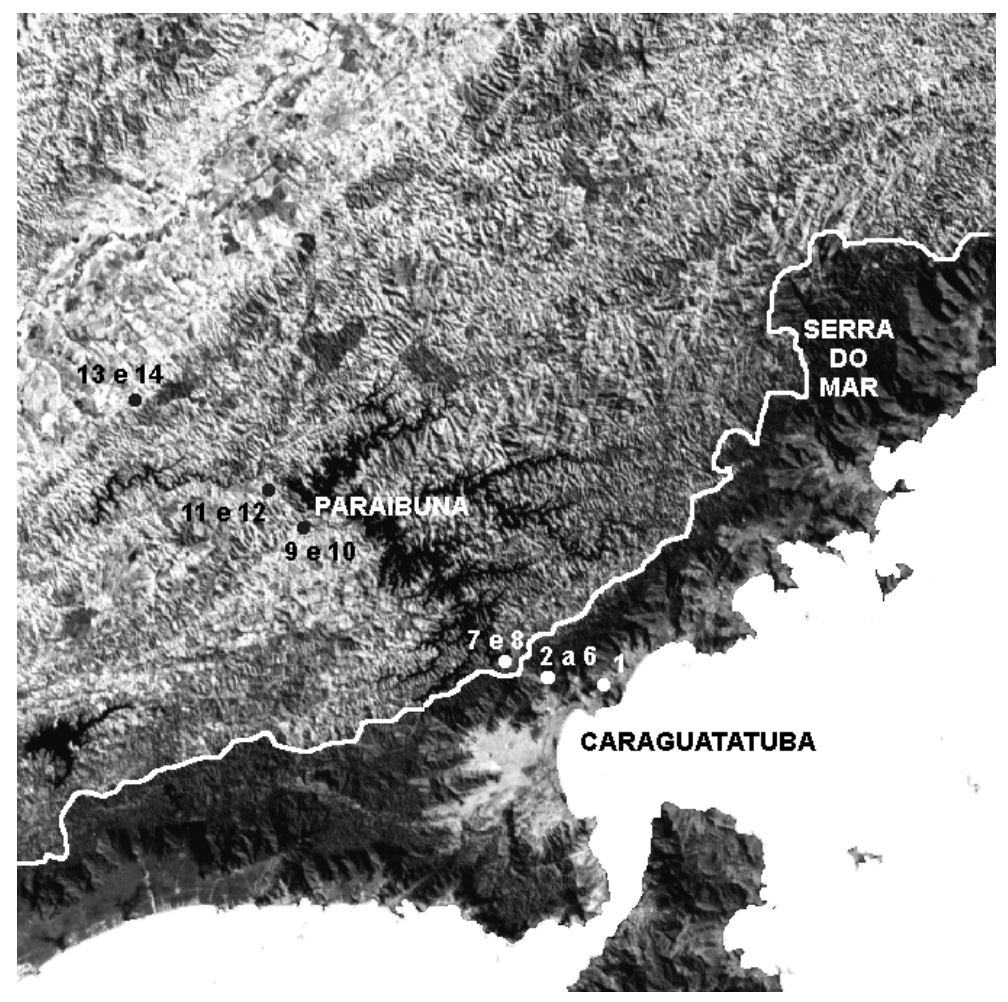

Figura 5 Localização dos pontos. 
COLÂNGELO, A. C. (2005). Magnitude-frequency and slope stability models. Revista do Departamento de Geografia, n. 16, p. 11-23.

Abstract: The first part of this article is dedicated to the magnitude-frequency approach, which represents a new light in Process Geomorphology assessment. Its proposal remounts to Wolman and Miller's work (1960), but gained a new force with the Ahnert's paper (1987), which integrates in a semilogarithm function the amount of effective contribution of a variety of events considered in a processes study. This approach is indistinctly applicable in all work scales and for all kinds of events, providing more accurate predictions in time and space. The second part refers to the evolution of models for slope stability, created in Soil Mechanics and adapted to Geomorphology, from Coulomb (1776) to Fredlund (1987). Surveyed data examples in a humid tropical area are presented in the two parts to illustrate the assertions and comments.

Key words: Magnitude-frequency analysis; Process analysis; Slope stability; Thresholds in Geomorphology.

Recebido em 7 de setembro de 2005, aceito em 2 de outubro de 2005.

\section{Referências}

AHNERT, F. (1987) An Approach to the Identification of Morphoclimates, In: Gardner, $\quad$. $\quad$ (ed.) International Geomorphology, p. 159-188.

BROOKS, S.M., ANDERSON M.G, ENNION, T., WILKINSON, P. (1999) Exploring the potential for physically-based models and contemporary slope processes to examine the causes of Holocene mass movement, In: Hergarten, S. e Neugbauer, $\mathrm{H}$. J. (eds.) Process Modeling and Landform Evolution. p. 205230.

CARSON, M.A. (1975) Thresholds and characterístics angles of straight slopes. In: Mass Wasting, 4th Ghelph Symposium on Geomorphology, Ontario.

CARSON, M.A. e KIRKBY, M.G. (1972) Hillslope, form and process. Cambridge University Press.

CHOWDHURY, R.N. (1978) Slope analysis, Elsevier, New York. 423p.

COLÂNGELO, A.C. (1990) Movimentos de massa e evolução geomorfológica das vertentes marginais no lago de barragem do Paraibuna, Mun. de Paraibuna - S.P. Dissertação de Mestrado, DG - FFLCH - USP. 118p.

COLÂNGELO, A.C. (1995a) Movimentos de massa e evolução geomorfológica das vertentes no alto vale do Paraíba do sul São Luis do Paraitinga - SP. Tese de Doutorado, DG - FFLCH - USP. 250p.

COLÂNGELO, A.C. (1995b) Os mecanismos de compensação e 0 equilibrio de forças na dinâmica dos materiais de vertente. In: Revista do Departamento de Geografia, n. 9 FFLCH-USP. p.13 $-20$.

COLÂNGELO, A.C. (1996a) Evolução de vertentes em meio tropical úmido: avaliação e mapeamento de limiares. In: Anais do I Simpósio Nacional de Geomorfologia, Uberlândia MG.
COLÂNGELO, A.C. (1996b) 0 modelo de feições mínimas, ou das unidades elementares de relevo: um suporte cartográfico para mapeamentos geoecológicos. In: Revista do Departamento de Geografia, $n^{\circ}$ 10, FFLCH-USP. p. 30-40.

COLÂNGELO, A.C. e CRUZ, O. (1997) Spatial magnitudefrequency index of mass movement event deposits in a humid tropical Precambrian plateau, and its connection with MFI of daily rainfall $\mathrm{In}$ : Fourth International Symposium on Geomorphology, Bologna, 28 de Agosto a 3 de Setembro.

COLÂNGELO, A.C. e O. CRUZ (2000) Índice de MagnitudeFreqüência Espacial de Movimentos de Massa num Planalto Tropical Úmido, Geousp, $n^{\circ}$ 08. p. 17-27.

COULOMB, C.A. (1776) Essai sur une application des régles des maximis et minimis a quelques problémes de statique relatifs á l'architecture. In: Memoire de La Academie Royale, vol.VII.

CROZIER, M. e GLADE, T. (1997) Magnitude and frequency of landslide events in New Zealand. In: Fourth International Symposium on Geomorphology, Bologna, 28 de Agosto a 3 de Setembro.

CRUZ, O. (1974) A serra do Mar e o litoral na área de Caraguatatuba - SP. Série teses e monografias, IGEOG - USP.

CRUZ, O. (1975) Evolução das vertentes nas escarpas da serra do Mar em Caraguatatuba - SP. An. Acad. Bras. Ciênc., Suplemento, $n^{\circ} 47$, Rio de Janeiro.

DE PLOEY, J., CRUZ, O., MODENESI, M.C. (1978) Resistences au cisaillement et conditions de glissements de terrain à Caraguatatuba et à Campos de Jordão. Colóquio Est. e Cart. de Form. Sup., São Paulo, vol.1.

DE PLOEY, J. e CRUZ, O. (1979) Landslides in the Serra do Mar, Brazil, Catena n.6. 
DE PLOEY, J. e GABRIELS, D. (1980) Measuring soil loss and experimental studies. In: Kirkby, M. J. and Morgan, R. P. C. (eds.), Soil erosion. J. Wiley e Sons. 312p.

DE PLOEY, J. (1981) The ambivalente effects of some factores some factors of erosions. Mem. Inst. Louvrain Lenvon, Belginn n. 31 p. 171-181.

DE PLOEY, J. KIRKBY, M. J. , AHNERT, F. (1991) Hillslope Erosion by Rainstorms - A magnitude-frequency analysis, earth surface processes and landforms, vol. 16. p.399-409.

DERBYSHIRE, E., GREGORY, K.J., HAILS, J.R. (1979) Geomorphological processes. Danson Westview Press.

FREDLUND, D.G. (1987) Slope stability analysis incorporating the effect of soil suction. In Slope Stability.

FREDLUND, D.G., MORGENSTERN, N.R., e WIDGER, R.A. (1978) Shear strength of unsaturated soils, Can. Geotech. Journal, n.15.

GREGORY, K. J. (1978) A physical geography equation. National
Geographer, $\mathrm{n}^{\circ} 12$.

HVORSLEV, J. (1936) Conditions for failure of remolded cohesive soils, Proc. First Int. Conf. of Soil Mech. and Found. Eng., Cambridge.

RUHE, R.V. (1975) Geomorphology, Houghton Mifflin Co., Boston. SIDLE, R.C., PEARCE, A.J., O'LOUGHLIN, C.L. (1985) Hillslope stability and land use. Am. Geogr. Union, Washington.

TEMPLE, P.H. e RAPP, A. (1972) Landslides in the Mgeta area, W. Uluguru mountains, Tanzania. Geogr. Ann., 50A (3-4), p.157194.

TERZAGHI, K. (1956) Theoretical soil mechanics, John Wiley e Sons.

VARGAS, M. (1970) Mecânica dos solos. McGraw - Hill do Brasil.

WOLMAN, M.G. e MILLER, J.P. (1960) Magnitude and frequency of forces in geomorphic processes, Journal of Geology, n.68, p.54-74. 